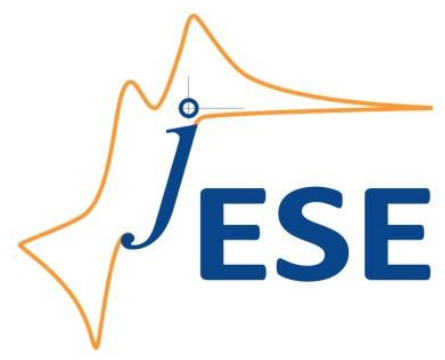

Open Access : : ISSN 1847-9286

www.jESE-online.org

Original scientific paper

\title{
Experimental determination of optimal clamping torque for AB-PEM fuel cell
}

\author{
Noor UI Hassan $* * *, \bowtie$ Murat Kilic***, Emin Okumus***, Bahadir Tunaboylu**,***, \\ Ali Murat Soydan* \\ *Nanotechnology Research Center, Gebze Technical University, Cayirova, Kocaeli 41420, Turkey \\ **Department of Industrial and System Engineering, Istanbul Sehir University, Istanbul, 34662, \\ Turkey \\ ***Tubitak Marmara Arastirma Merkezi (MAM), Baris Mah., Dr. Zeki Acar Cd No:1, Gebze \\ Merkez/Kocaeli, Turkey \\ Corresponding Author: noormct@hotmail.com
}

Received: July 6, 2015; Revised: March 11, 2016; Accepted: April 18, 2016

\begin{abstract}
Polymer electrolyte Membrane (PEM) fuel cell is an electrochemical device producing electricity by the reaction of hydrogen and oxygen without combustion. PEM fuel cell stack is provided with an appropriate clamping torque to prevent leakage of reactant gases and to minimize the contact resistance between gas diffusion media (GDL) and bipolar plates. GDL porous structure and gas permeability is directly affected by the compaction pressure which, consequently, drastically change the fuel cell performance. Various efforts were made to determine the optimal compaction pressure and pressure distributions through simulations and experimentation. Lower compaction pressure results in increase of contact resistance and also chances of leakage. On the other hand, higher compaction pressure decreases the contact resistance but also narrows down the diffusion path for mass transfer from gas channels to the catalyst layers, consequently, lowering cell performance. The optimal cell performance is related to the gasket thickness and compression pressure on GDL. Every stack has a unique assembly pressure due to differences in fuel cell components material and stack design. Therefore, there is still need to determine the optimal torque value for getting the optimal cell performance. This study has been carried out in continuation of development of Air breathing PEM fuel cell for small Unmanned Aerial Vehicle (UAV) application. Compaction pressure at minimum contact resistance was determined and clamping torque value was calculated accordingly. Single cell performance tests were performed at five different clamping torque values i.e 0.5, 1.0, 1.5, 2.0 and $2.5 \mathrm{~N} \mathrm{~m}$, for achieving
\end{abstract}


optimal cell performance. Clamping pressure distribution tests were also performed at these torque values to verify uniform pressure distribution at optimal torque value. Experimental and theoretical results were compared for making inferences about optimal cell performance. A clamping torque value of $1.5 \mathrm{Nm}$ was determined experimentally to be the best for getting optimal performance as well as uniform pressure distribution for this specific fuel cell.

\section{Keywords}

Air breathing PEM fuel cell; Stack clamping torque; Compaction pressure; Contact resistance;

Optimal cell performance

\section{Introduction}

Due to the growing concerns on the depletion of petroleum based energy resources and climate change, fuel cell technologies have received much attention in recent years owing to their high efficiencies and low emissions. Fuel cells, which are classified according to the electrolyte employed, are electrochemical devices that directly convert chemical energy stored in fuels such as hydrogen, to electrical energy. Its efficiency can reach as high as $60 \%$ in electrical energy conversion and overall $80 \%$ in co-generation of electrical and thermal energies with more than ninety percent reduction in major pollutants [1].

The stack design and cell assembly can significantly affect the performance of fuel cells. Adequate contact pressure is needed to hold the fuel cell stack components together to prevent leaking of the reactants between the layers and minimize the contact resistance between layers. The clamping force is equal to the force required to compress the gasket, fuel cell layers, and internal force. The assembly pressure affects the characteristics of the contact interfaces between components due to thin dimensions and the low mechanical strength of fuel cell layers versus the gaskets, bipolar plates, and end plates. The most important goal in the stack design and assembly is to achieve appropriate and uniform pressure distribution. If inadequate or non-uniform assembly pressure is used, there will be stack sealing problems, such as fuel leakage, internal combustion, and unacceptable contact resistance. Too much pressure may damage the fuel cell layers, resulting in a broken porous structure and a blockage of the gas diffusion passage. In both cases, it will decrease the cell performance as well as stimulating degradation. Every stack has a unique assembly pressure due to differences in fuel cell materials and stack design.

Several studies were carried out to determine optimal clamping force in order to achieve optimal fuel cell performance. Bates et al performed simulation of a single cell and 16-cell fuel cell stack at various clamping pressures. They performed experimental testing of clamping pressure effects on a 16-cell stack by placing a thin pressure-sensitive film between GDL and bipolar plate. They applied clamping pressure using various loads, durations, and two types of GDL resulting in detailed 3D plots of stress and deformation [2]. Chang et al. [3] measured the electro-physical properties of the gas diffusion layer (GDL) such as porosity, gas permeability, electrical resistance and thickness using a special designed test rig under various clamping pressure levels. They developed correlations for the gas permeability of the GDL in terms of the clamping pressure. Moreover, they also measured contact resistance between the GDL and the bipolar (graphite) plate under various clamping pressures. They showed that increasing the clamping pressure reduces the interfacial resistance between the bipolar plate and the GDL that enhances the electrochemical performance of a PEM fuel cell. On the other hand, at the high clamping pressure levels, increasing the clamping pressure not only reduces the Ohmic resistance but also narrows 
down the diffusion path for mass transfer from gas channels to the catalyst layers [3]. Changes in PEM fuel cell performance have been reported as a function of compression pressure resulting from torque applied on bolts [4]. Authors used three different types of GDLs and reported that, the optimum is related to the gasket thickness and the measured compression pressure on the diffusion layer. Wang et al. [5] studied the effect of internal pressure distribution on the performance of a PEM fuel cell. They designed a pressurized endplate. They used pressure sensitive films to measure the pressure distribution for both conventional and newly designed end plates and achieved improved cell performance with newly designed end plate [5]. Zhou et al. [6] studied the effect of clamping force on the performance of PEM fuel cell with inter-digitated gas distributors considering the interfacial contact resistance, the non-uniform porosity distribution of the gas diffusion layer (GDL) and the GDL deformation. They reported that there exists an optimal clamping force to obtain the highest power density for the PEMFC with the inter-digitated gas distributors [6]. Finite element analysis (FEA) procedures were established for a PEM single cell with point stack assembly method [7]. Yu et al. [8] designed a new asymmetric composite sandwich end plate made of carbon fiber reinforced composite and glass fiber reinforced composite with a pre-curvature generated by the residual thermal deformation, which yields the required pressure distribution in the stack when the end plates are fastened by the clamping device [8]. Liu et al. developed a methodology based on FEA model and Monte Carlo simulation to investigate the effect of dimensional error of the metallic Bipolar Plate (BPP) on the pressure distribution of gas diffusion layer (GDL) [9]. Lin et al. reported the effect of gas diffusion layer compression on the performance in a proton exchange membrane fuel cell [10]. Zhou et al. reported the effect of non-uniformity of the contact pressure distribution on the electrical contact resistance in PEM fuel cells. For a given clamping force, the minimum electrical contact resistance is expected by making the pressure distribution as uniform as possible [11]. Avasarala et al. [12] studied the effect of surface roughness of composite bipolar plates on the contact resistance of a proton exchange membrane fuel cell. They observed that most of this contact resistance is governed by electrical properties of the interface layer between the contacting surfaces [12]. Wen et al. [13] carried out an experimenttal study of clamping effects on the performance of a single proton exchange membrane fuel cell and a 10-cell stack. They found that the uniformity of the contact pressure distribution, the ohmic resistance and the mass transport limit current, had highly linear correlations with the mean contact pressure [13]. Montanini et al. measured the clamping pressure distribution in polymer electrolyte fuel cells using piezo-resistive sensor arrays and digital image correlation techniques [14]. Xing et al. [15] reported a three-dimensional model to investigate the effect of assembly clamping pressure on the GDL properties and thus on the performance of PEM fuel cells, and to determine the optimum clamping pressures when the cell is operated under different operating voltages. They suggested that the optimum clamping pressures increase when the operating voltage increases [15].

\section{1. Clamping torque calculation theory}

Clamping torque on the bolts can be calculated from the following equation [17]:

$$
\begin{aligned}
& T_{\mathrm{t}}=F_{\text {clamp }} K_{\mathrm{b}} D_{\mathrm{b}} / N_{\mathrm{b}} \\
& F_{\text {clamp }}=P_{\mathrm{c}} A
\end{aligned}
$$

where, $T_{\mathrm{t}}$ is the tightening torque in $\mathrm{Nm}, F_{\text {clamp }}$ is the clamping force in $\mathrm{N}, K_{\mathrm{b}}$ is the friction coefficient, $D_{\mathrm{b}}$ is the bolt nominal diameter in $\mathrm{m}$, and $N_{\mathrm{b}}$ is the number of bolts. $F_{\text {clamp }}$ is a function of clamping pressure $-P_{\mathrm{c}}$ and cell active area - $A$. Colleen Spiegel et al. [18], also considered other 
important dimensions for calculating clamping torque i.e. material properties of cell components and bolts, geometry of holes, stiffness of the components, stack thickness, and contact resistance between BPP and GDL etc. The torque value obtained by these calculations give us range of clamping torque to be applied, but still there is need to find optimum torque value which will give optimum cell performance. A clamping torque value of $1.2 \mathrm{~N} \mathrm{~m}$ was calculated for our fuel cell stack. This study focused experimental procedure for obtaining optimum clamping torque. The effects of clamping force can be summarized in the following chart (Figure 1).

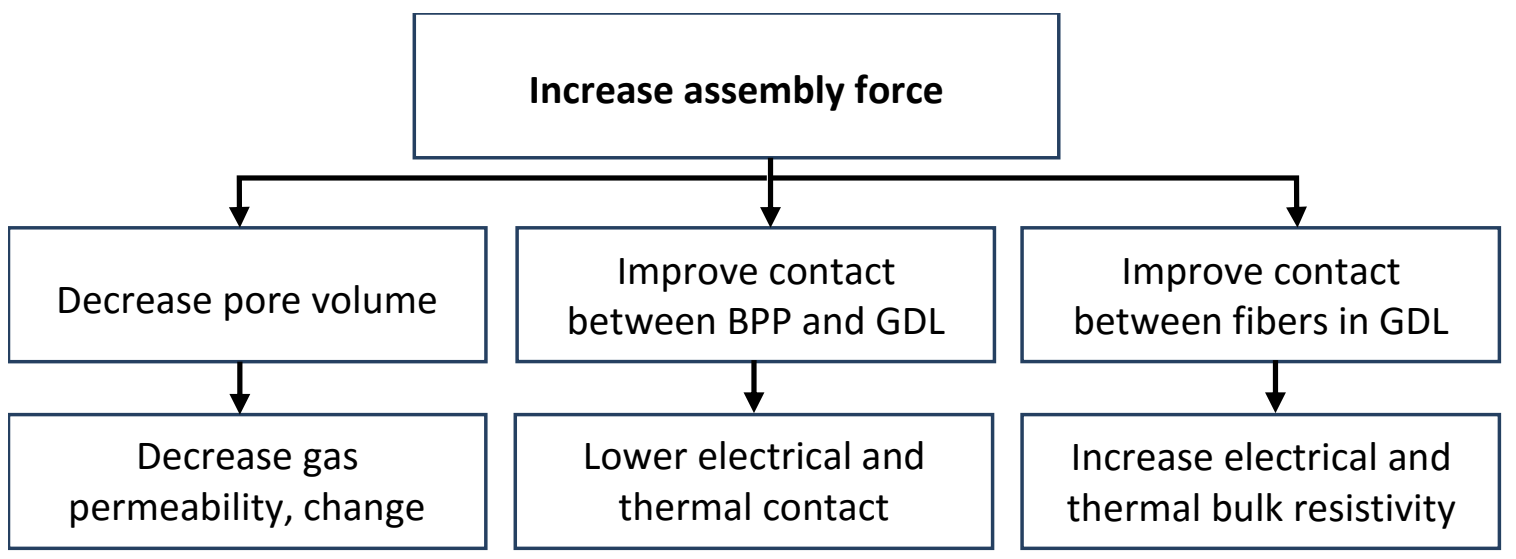

Figure 1. Effects of increasing assembly pressure

\section{2. Contact resistance and clamping pressure}

The contact resistance between BPP and GDL can be deduced as measured by various authors in literature $[19,20]$. The governing equation for calculation of contact resistance is given below;

$$
R_{\text {contact }}=\left(R_{\mathrm{es} 1}-R_{\mathrm{es} 2}-R_{\mathrm{BPP}}-R_{\mathrm{GDL}}\right) / 2
$$

where, $R_{\mathrm{es} 1}$ and $R_{\mathrm{es} 2}$ are measured resistances from Setup 1 and Setup 2, respectively as shown in the Figure 2. $R_{\mathrm{BPP}}$ is the bulk resistance of graphite BPP and $R_{\mathrm{GDL}}$ is the bulk resistance of GDL. $R_{\mathrm{BPP}}$ and $R_{\mathrm{GDL}}$ are calculated according to their bulk resistivity. Contact resistance was observed to be minimum at a value of $140 \mathrm{~N} / \mathrm{m}^{2}$.

a

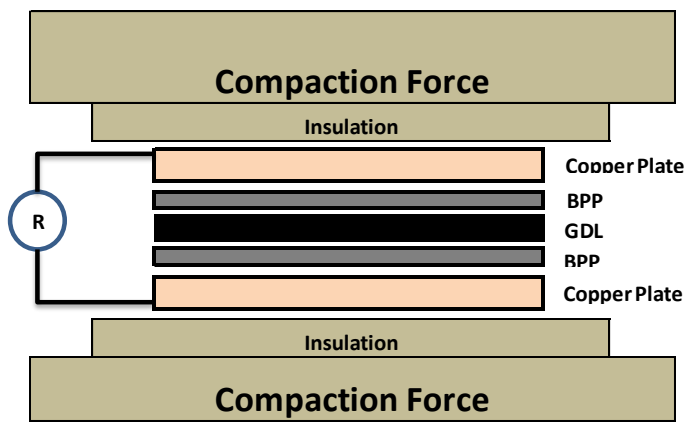

b

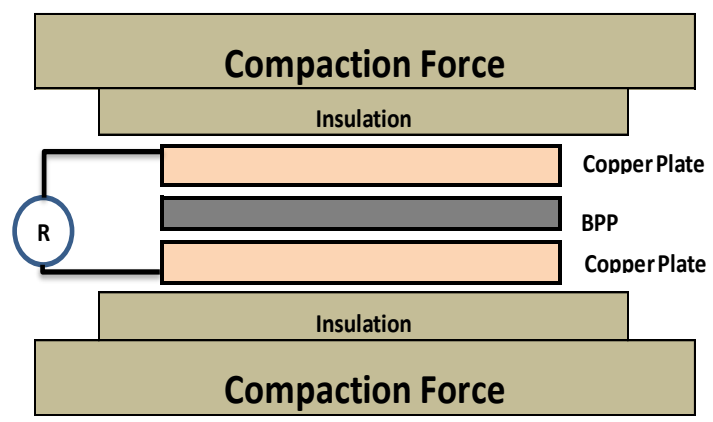

Figure 2. A schematic diagram of the experimental apparatus used for contact resistance measurement: (a) Setup 1 (b) Setup 2

\section{Experimental}

\section{1. Materials, method and assembly}

Graphite bipolar plates with double serpentine flow channels for anode and parallel flow channels for cathode side were prepared by machining. Commercially available Nafion 212 
membrane was used for our fuel cell. Custom made MEAs were prepared with Pt loading of $0.6 \mathrm{mg} \mathrm{cm}^{-2}$, for both anode and cathode side. Gasket thickness was calculated based on the thicknesses of membrane and GDL. Silicon gasket with a thickness of $0.125 \mathrm{~mm}$ was used. Polymer (PTFE) end plates were used for providing sufficient contact force between the components. A total quantity of eight $M 4 \times 20$ bolts was used to clamp the cell components. Copper sheets with a thickness of $0.8 \mathrm{~mm}$ were used as current collectors. Several MEAs were prepared at the same conditions to test designed fuel cell. The active areas of the MEA was $20 \mathrm{~cm}^{2}$ $(10 \times 2 \mathrm{~cm})$. Other components were also prepared as per designed dimensions with acceptable properties as defined by Department of energy (DOE). Finally, a single cell was assembled for testing at different clamping torque values.

\section{2. Contact resistance measurement}

Different experimental setups have been used by authors to measure the contact resistance $[19,20]$. We used the similar procedures to measure the contact resistance. BPP specimen was inserted between two carbon papers (GDL) and all sand-witched between copper plate current collectors. A series of compression pressures from 0.5 to $3 \mathrm{MPa}$ were applied and the corresponding contact resistances were measured. Under each clamping pressure, the contact resistance measurements were repeated four times to obtain the average values.

\section{3. Pressure distribution}

Pressure distribution measurement method as used by several authors $[7,13,16]$ has been followed for our experiment. To get the pressure distribution, tests were conducted on our hardware with eight bolts at five different applied torque values, from 0.5 to $2.5 \mathrm{~N} \mathrm{~m}$ with an increment of $0.5 \mathrm{~N} \mathrm{~m}$. A rectangular piece of film was cut with the dimensions similar to BPP used and was inserted between the membrane electrode assembly (MEA) and gas diffusion layer (GDL). Firstly, $0.5 \mathrm{~N} \mathrm{~m}$ torque was applied on each bolt of the cell structure in a certain sequence. After approximately five minutes, the bolts were loosened and the film was taken out. Same procedure was repeated with other torque values and pressure distribution was observed.

\section{3. Polarization and power curves}

The experiments were hold at $60^{\circ} \mathrm{C}$ while hydrogen and oxygen were purged fully humidified at $50{ }^{\circ} \mathrm{C}$. The gas flow rates were kept constant, both for the anode and cathode and were $0.2 \mathrm{~L} \mathrm{~min}^{-1}$ and $0.4 \mathrm{~L} \mathrm{~min}^{-1}$, respectively. The MEAs were conditioned before recording data. Polarization curves were obtained while decreasing the potential slowly by withdrawing current. Polarization data was recorded after six continuous cycles.

\section{Results and discussion}

\section{1. Pressure distribution results}

As the pressure was applied, microcapsules on the pressure sensitive film were broken and a color-forming material was released and absorbed on the film. The color (red) intensity of the film is directly related to the amount of applied pressure. The greater the pressure, the more intense the color. After waiting another five minutes, the fuel cell was opened, and the pressure distribution was observable by the color (red) density pattern formed on the film. It is observed that pressure distribution was uniform at a clamping torque of $1.5 \mathrm{~N} \mathrm{~m}$ compared to other torque values. Figure 3 below, shows the experimental results obtained at 0.5 and $1.5 \mathrm{~N} \mathrm{~m}$ torque values, respectively. 
a

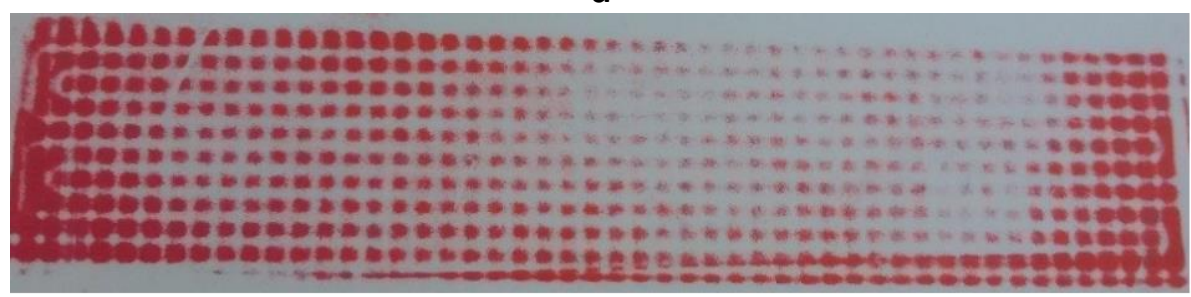

b

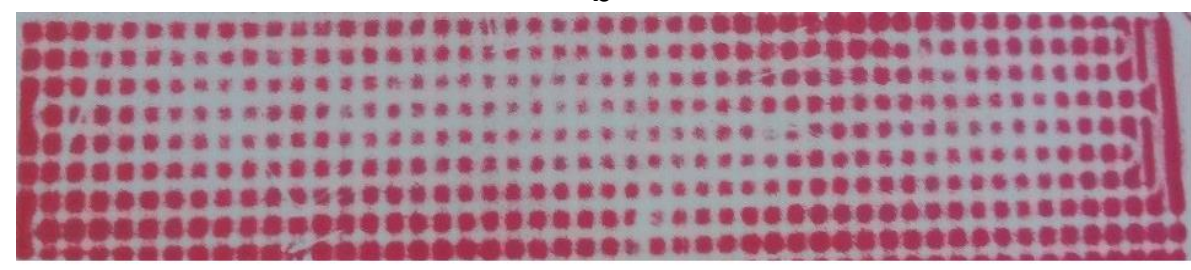

Figure 3: Pressure distribution results, (a) torque applied $0.5 \mathrm{~N} \mathrm{~m}$, (b) torque applied $1.5 \mathrm{~N} \mathrm{~m}$

\section{2. Single cell performance}

Upon obtaining assembly pressure effects on mass transfer resistance and contact resistance above, the overall PEM fuel cell performance was obtained experimentally, as shown in Figure 4.

a

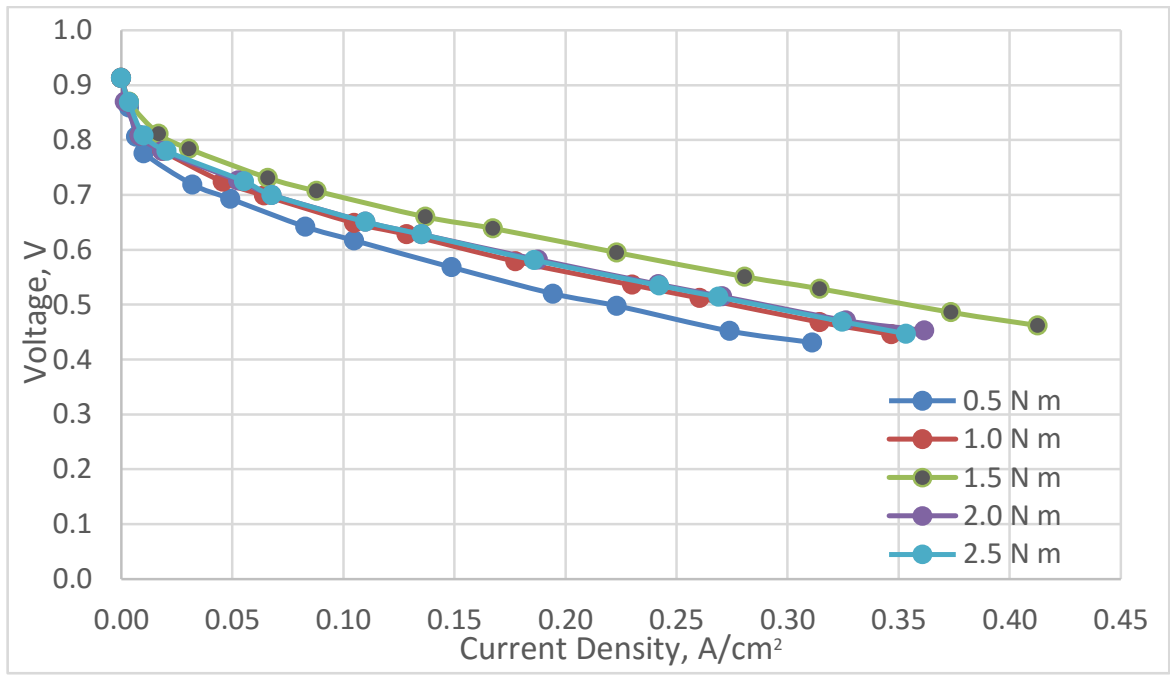

b

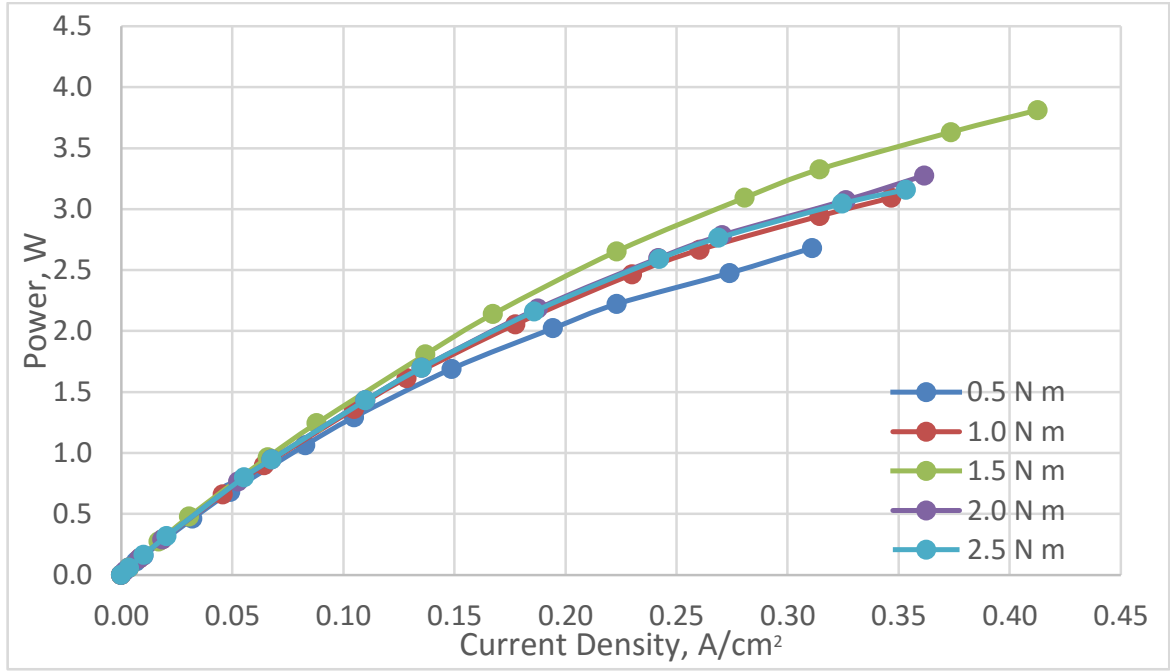

Figure 4. Experimental results: $\boldsymbol{a}$ - polarization at different clamping torque values, $\boldsymbol{b}$ - power curves at different torque values. 
The fuel cell performance lowers at low clamping torque values. As we increase the clamping torque, the cell performance increases and again starts decreasing after a certain torque value. However, an optimum assembly pressure exists within the lower pressure region. This optimal value is the result of the competing effects of contact resistance and mass transfer resistance. When the assembly pressure is very low, contact resistance could be high and reverse the effect of low mass transfer resistance. Obviously, an assembly pressure near this optimum value is preferred. Furthermore, if surface parameters of the BPP change, especially when the surface standard deviation becomes larger, the contact resistance tends to be higher. The optimum assembly pressure could then shift to a higher level, which can be achieved in practical assembly processes. For a lower value of assembly torque $(0.5 \mathrm{~N} \mathrm{~m})$, the compression pressure is not sufficient to compress GDL to gasket level and cause fuel leakage as well as a poor contact between GDL and bipolar plate. On the other hand, higher assembly torque $(2.5 \mathrm{~N} \mathrm{~m})$ leads to smaller porosity, imposing more impedance to gas transfer. Thus, the current density generated under the land area is less and has more variation in its distribution resulting in lower cell performance. The optimum clamping torque $(1.5 \mathrm{~N} \mathrm{~m})$ is a negotiation between contact resistance and mass transfer due to GDL compression giving the best cell performance. Experimental results obtained at different clamping torque values are shown in the Figure 4.

\section{Conclusion}

In order to study the effects of assembly pressure on the performance of PEM fuel cells, theoretical calculations were made for calculating the clamping torque value. Experimental procedures were carried out for obtaining the optimized clamping torque giving optimal performance. Fuel cell performance has been observed by polarization and power curves. It has been observed that assembly pressure has noteworthy effects on PEM fuel cell performance. In a broader view, low assembly pressure causes fuel leakage problems and an increase in contact resistance between bipolar plates and GDL, consequently decreasing fuel cell performance. Whereas, high assembly pressure increases mass transfer resistance. Current density decreases significantly with an increase of assembly pressure. However, by incorporating the competing effects of electrical contact resistance, the overall performance first increases and then decreases with the increase of assembly pressure. There exists an optimum assembly pressure, in the lowerpressure region, at which fuel cell performance is optimum.

Acknowledgment: We are thankful to Dr. Osman Okur and Dr. Suha Yazici who provided us financial as well as equipment support to carry out this study at TUBITAK MAM (Energy Center Hydrogen and Fuel Cell Laboratory) Gebze, Turkey.

\section{References}

[1] D. Papageorgopoulos, An Introduction to the 2010 Fuel Cell Pre-Solicitation Workshop in DOE fuel cell pre-solicitation workshop. Department of Energy, Lakewood, Colorado; March 16, 2010.

[2] A. Bates, S. Mukherjee, S. Hwang, S.C. Lee, O. Kwon, G.H. Choi, S. Park, International Journal of Hydrogen Energy 38 (2013) 6481-6493.

[3] W.R. Chang, J.J. Hwang, F.B. Weng, S.H. Chan, Journal of Power Sources 166 (2007) 149154.

[4] W. Lee, C.H. Ho, J.W. Van-Zee, M. Murthy, Journal of Power Sources 84 (1999) 45-51.

[5] X. Wang, Y. Song, B. Zhang, Journal of Power Sources 179 (2008) 305-309.

[6] P. Zhou, C.W. Wu, G. J. Ma, Journal of Power Sources 163 (2007) 874-881. 
[7] S.J. Lee, C.D. Hsu, C H. Huang, Journal of Power Sources 145 (2005) 353-361.

[8] H.N. Yu, S.S. Kim, J.D. Suh, D.G. Lee, Composite Structures 92 (2010) 1498-1503.

[9] D. Liu, L. Peng, X. Lai, International Journal of Hydrogen Energy 34 (2009) 990 - 997.

[10] J.H. Lin, W.H. Chen, Y.J. Su, T.H. Ko, Fuel 87 (2008) 2420-2424.

[11] P. Zhou, P. Lin, C. W. Wu, Z. Li, International Journal of Hydrogen Energy 36 (2011) 6039 6044.

[12] B. Avasarala, P. Haldar, Journal of Power Sources 188 (2009) 225-229.

[13] C.Y. Wen, Y.S. Lin, C.H. Lu, Journal of Power Sources 192 (2009) 475-485.

[14] R. Montanini, G. Squadrito, G. Giacoppo, Journal of Power Sources 196 (2011) 8484-8493.

[15] X.Q. Xing, K.W. Lum, H.J. Poh, Y.L. Wu, Journal of Power Sources 195(2010)62-68.

[16] H. Mehboob, P.M. Kyun, K.A. Soo, B.A. Zai, R. Ali, Third European fuel cell technology \& application Piero Lunghi Conference, Rome, Italy, 2009 EFC- 17063 pp.95.

[17] F. Barbir, PEM Fuel Cells: Theory and Practice, Elsevier/Academic Press, Burlington, MA, USA, 2005, pp.143-180;.

[18] C. Spiegel, PEM Fuel Cells: Modeling and Simulation Using MATLAB, Elsevier/Academic Press, Burlington, MA, USA, 2008.

[19] V. Mishra, F. Yang, R. Pitchumani, ASME Journal of Fuel Cell Science and Technology, 1 (2004) 2-9.

[20] L. Zhang, Y. Liu, H. Song, S. Wang, Y. Zhou, S. J. Hu, Journal of Power Sources 162 (2006) 1165-1171.

(C) 2016 by the authors; licensee IAPC, Zagreb, Croatia. This article is an open-access article distributed under the terms and conditions of the Creative Commons Attribution license (http://creativecommons.org/licenses/by/4.0/) 